\title{
Designing for a Moving Target
}

\author{
Gerrit C. van der Veer
}

Received: 11 August 2011 / Accepted: 10 January 2012 / Published online: 31 January 2012

(C) The Author(s) 2012. This article is published with open access at Springerlink.com

\begin{abstract}
User centered design is a relatively young design approach. Over the years, user centered design changed its scope. However, the concept of usability does not just expand by broadening the view on ease of use and learning. Experience is added in the nineties and in 2006 we find Apple suggest its iPod users to "Enjoy Uncertainty." The history of user centered design (or human-computer interaction, or cognitive ergonomics) shows the development of the design approach as a movement in different dimensions:

- from the reign of functionality to attention to individual users in context;

- from user control to experience and entertainment; and

- from a culturally defined cost-benefit goal to perspective on a multitude of design cultures and cultures of use.
\end{abstract}

\section{Introduction}

User centered design is a relatively young design approach. In fact, the concept of "usability" can be traced back to General Motors [12]. Over the years user centered design changed its scope. The (German) DIN norms of 1988 consider suitability for the task, conformity with user expectations, and user controllability to be the defining characteristics of usable systems [9]. The European Agency for Safety and Health at Work, just 3 years later [5] includes appropriate format and pace of information presentation as well as ease of use in the definition. The ISO standard 9241 part 10 [6] broadens the view by including self-descriptiveness

G.C. van der Veer $(\bowtie)$

Open University of the Netherlands, Heerlen, The Netherlands

e-mail: gerrit@acm.org and suitability of learning. Interestingly, the "official" visions on user centered design criteria started as national efforts and gradually expanded to true international standards. However, the concept of usability does not just expand by broadening the view on ease of use and learning. Experience is added in the nineties [14] and in 2006 we find Apple suggest its iPod users to "Enjoy Uncertainty."

The author's experiences of 30+ years of teaching user centered design in many countries like Romania, Spain, Italy, and the Netherlands, in curricula like Cognitive Psychology, Ergonomics, Computer Sciences, and Architecture, reflect this changing world. Different national and discipline-based education systems combined with different cultural values regarding the balance of benefit to individual users versus economic costs of design and implementation lead to a growing awareness that culture itself is an issue. In parallel to this personal development contacts with colleague in education worldwide showed a growing diversity of relevant knowledge domains. Where first mainly Ergonomics and Cognitive Psychology contributed, Computer Science and its developing specialism Software Engineering soon showed to be relevant. In the same way Industrial Design joined the field as did Multi Media Design and various artistically grounded design disciplines.

Another continuing basis for growing understanding is the ongoing development of international societies and related conference series in this field. Starting with mostly single country based developments of a user centered focus on artifact design in the "classical" ergonomics, visionaries like Brian Shackel [10] initiated conferences focusing on the relation between human users and the, at that time emerging, computer. In this way, the first European Conference on Cognitive Ergonomics was organized in 1982 in Amsterdam, the first conference on Human factors in Computing systems was in the same year in Gaithersburg, and the first 
INTERACT was held in 1984 in London. Each of these led to the subsequent foundation of a society: resp., the European Association of Cognitive Ergonomics EACE, ACM's originally mainly North American Special Interest Group on Computer Human Interaction SIGCHI, and the officially international but in fact at the start Europe focused IFIP TC 13 on Human Computer Interaction. Each of these professional societies (with their conference series that currently still are alive and running) started with their own visions and focus and each developed a growing awareness of differences in occupationally as well as geographically different cultural aspects of user centered design.

In fact the history of user centered design (or humancomputer interaction, or cognitive ergonomics) shows the development of the design approach as a movement in different dimensions:

- From the reign of functionality to attention to individual users in context;

- from user control to experience and entertainment; and

- from a culturally defined cost-benefit goal to perspective on a multitude of design cultures and cultures of use.

\section{Design for Use}

One of the unique characteristics of human beings is their competence regarding artifacts:

1. Humans regularly use artifacts as tools. This characteristic they share with several types of animals, but those will only use artifacts if these happen to be available;

2. humans build artifacts for use, where artifacts may be physical tools, but also non-physical or "conceptual", like laws, social structures, political systems, norms, languages, stories, etc.;

3. humans design artifacts by developing visions on future situations where new artifacts could be used, considering needs, opportunities, and a future context or use.

The combination of these three competences seems to unique for human culture.

The way the roles related to these three aspects are shared or divided between human actors, however, strongly depends on the cultural situation. In this respect, "culture" should be understood in a broad way. Culture may be identified based on region (Europe versus N. America, Dutch versus Belgian); language (Flemish vs. French speaking Belgians); profession (Cognitive Psychologists versus Software Engineers); Age group; religion or political positions; etc. In fact, most people participate at any time of their life in several different cultures: living in a certain country, feeling related to a church, being a member of a professional community, as well as having family relations.
When looking around the world and through the history of mankind one finds diversity though there seems to be a one-way development from closed tribal societies to the modern urban world:

In closed societies and relatively simple worlds everybody knows everybody, people strongly depend on each other, teach each other and learn from each other, and support each other in many ways. In this type of society there is no strong separation between the use, the making of, and the design of artifacts. The early human hunter designed, built, and used his own flint stone weapons. In order to provide a stable supply of food, early farmers selected, grew, and ate their own types of crops and domesticated their own cattle. A recently discovered archeological fund dated 40 thousand years ago (the "oldest" musical instrument; [18]) which is in no way unique in its date and the type and proficiency of the artifact, shows that in those early days where human tribes can be estimated to have sizes of less than 150 individuals [8] both the use, the building, and the design were at a level that does not differ strongly from the 20th century.

To some extent, the same situation seems to be true in current isolated rural societies where villagers design, develop, and use their own infrastructure in relation to their own cultural values and the habits developed.

The urban world, of which the western society is the prototypical example, there is often a split between the use of artifacts and the making of them. Most "working" adults (i.e., those who contribute to their own support as well as to the economy of the society) have specified roles in relation to the use of artifacts. A small minority of building expert make the tools, an (often considerable larger) group of others contribute to the maintenance of the society (including the provision of facilities for leisure) by using the pre-fabricated tools.

In addition this world shows a split between the making of artifacts and the actual design of these. Design often is related to a professional specialism, whether artistic, scientific, or engineering. In fact real novel design seems in many cases related to expertise in various unrelated disciplines.

Obviously, the history of mankind shows many and long periods where these splits are not yet complete. In European Gothic architecture we may observe that only the global architecture of a building was designed by a major architect but detailing the decorations of panels, or window grids, or the iron ornaments of hinges, were in fact the unique creation of the various stone cutters, wood cutters, blacksmiths etc. And even in the early part of the 20th century a photographer would still be an expert in choosing, preparing, and selectively applying his own chemical solutions to develop effects that current Photoshop experts are trying to reach. In a similar way the early users of sewing machines were able to apply the tool kit that came with the machine to fine tune and re-program their tools. 


\section{Design Aims at Users}

As soon as the user and the designer are no longer the same person (irrespective of the identity of the maker) the designer needs to take the audience into account. In relatively closed societies this may in fact be implicit. As long as the context of use and the contest of design are more or less identical there is no notion of a potential problem. However if we look at such situations from a distance (e.g., in time) we are able to notice that a first strong issue of "usability" is related to the culture of the user group. In this way we will notice cultural variation in (1) values and norms; (2) experience and esthetics; and (3) language symbols and meanings. As these variations turn out to be relevant issues even in current day user centered systems design, we will first give an example of each. Being aware of these issues from observing remote cultures may help in current day design.

1. Values are the basis for common choices, preferences, and related satisfaction in using artifacts in a culture [15]. In the Archaic period if the Hellenic culture in Greece, it was acceptable to depict the human male nude. Representing the human female, however, was only considered proper if dressed. The related norms (the type of dress usually worn when in public) defined the way women were sculpted, whereas men were normally represented without clothes. Norms are only derived from the values, and can be changed, e.g. by design that takes the values in consideration. Fashion designers know this, though they often try out the elasticity of current values in "daring" creations.

2. Experience points to the way individual people understand, feel, appreciate, and interact with, artifacts, based on their current needs as well as the context and culture [23]. A derivative of experience is esthetic value, i.e., the way people appreciate the perceivable aspects of an artifact that is experienced (interpreted) in relation to the cultural basis of the experience [11]. As an example, take the 18th century in Western Europe and look for paintings of musicians: e.g., William Hogarth's engravings represent street musicians with their coarse and purely functional looking instruments, whereas a "society" painter like Rose Adelaide Ducreux depicts herself playing an excessively decorated Louis XVI harp.

3. Language can only be really understood if the audience is able to identify the symbols and their meaning. In fact, what is a symbol in a certain culture need not be one to a member of another culture. For most theater public, the color of the theater seats may have some esthetic value, but no symbolic meaning. A professional stage designer or theater director, however, knows that the color of fabric in the theater has a different meaning for different cultures of actors: Italian actors will refuse to play when the color purple is clearly visible from the stage, since "purple means theatrical disaster" [24] dating back from a period where the catholic church banned theater during the 40 days prior to eastern, the period where the clergy wore purple. French actors read the same meaning in the symbol of green fabric (and, consequently, will refuse to perform) referring to the legend [3] about Molière dying on stage wearing a green costume.

\section{Interaction Design-A Quick Repeat of History}

Even though interaction design as a systematic design approach is relatively young, it seems the history of human design, manufacturing, and use of artifacts repeats here. Certainly related to the emerging systematic attention to usercentered design referred to in the introduction, the first period can be characterized as straight forward and intentional user participation. The first computer users were mathematicians or people who needed complex information processing (the analysis of census data, complex statistical modeling and testing, ballistic analysis). These users were able to program their relatively primitive machines, and their solutions were often characteristic for their professionalism. They certainly pushed the development of machine architecture as well as machine languages.

At the start of the 80s computer systems became more widely available (in fact the first PCs entered offices, schools, and even hobby clubs) and a new type of users emerged. In general those were users who needed the machines for their jobs. In most cases they did not invent their jobs nor the procedures and tools. A major criterion was that the new tool would support the job and improve speed, performance, or economic results. Functionality for supporting the users' job was the key. Many systems in those days were dedicated to a single job: word processors, lath turning planning and monitoring tools, and teaching machines. This is the era where norms and standards were needed to support the workers' wellbeing.

In parallel to the development of hardware, around 1990 small and really portable machines conquered the market, the internet developed into an open network that was quickly supporting the World Wide Web. Uncountable Information systems were in fact available for everyone everywhere at any time. New design problems emerged: people in different situations were invited to use the same artifacts, and people were enabled and, hence, actually embarked in collaboration supported by, and through, technology. Collaboration, in this way, developed to complex processes, and people needed help with many issues, like version control, situational awareness, or data retrieval. Design approaches in this period featured new insights like contextual design [2] and distributed cognition $[7,16]$.

The early years of our new millennium show yet another challenge to design. During the January 2010 launch of the 
new iPad line, Apple CEO Steve Jobs announced that Apple had sold a landmark 250 million iPods since the release of the original iPod in 2001 [1]. Experience now is the new criterion and, at least in the view of Apple, enjoying uncertainty seems to balance user control over the artifacts used.

To summarize, the use of information systems in our brief history seems to develop from experts, developing their own tools, who needed command languages and operating systems with dedicated functionality to match their expertise; to users everywhere, wanting reactive, proactive, and intelligent environments as part of their everyday situation, their culture, and their organizations. These users do not care what is inside their black boxes (often colored after the style of their permanently changing cultures) as long as the experience serves their current purposes. The complete separation of design, building, and use brings an expanding issue of usability. The singular request for functionality in the $70 \mathrm{~s}$ has been complimented with a need for ease of use and for learnability, and finally for intended (by industry and clients of design) and lived (by all users) experience.

\section{Ever Changing Worlds}

At the same time that new technologies become available with continuing speed we perceive cultures of use merge, we see new cultures arise, and we find our users to move between these cultures. Social "services" are a relatively new development in our computer-supported networked world. Social network systems like Skype, LinkedIn, Twitter, Plaxo, Flickr, or Facebook, each develop their own networking culture. At the same time studies show that some of them are popular in certain parts of the networked globe: In 2005 Flickr was used all over Nord-West Europe and mainly central areas of the USA [4]; in 2007 Twitter lived mainly in the USA, All of Europe, and Japan [20]; Facebook finds its users especially in East USA and in the UK [13].

Once people are members of these networks they experience unexpected and unwanted attempts to be followed by unknown people or to be swallowed by ever growing structures of relationships. Some users feel this is threatening their privacy or this adds a useless burden in their online lives. A new phenomenon is a tool to forever quit one or more of these social networks. The Suicide Machine (suicidemachine.org; [21]) allows tormented users to disappear permanently from at least (at the end of 2011) Facebook.com, MySpace.com, Twitter.com, and LinkedIn.com.

The web is only part of the story. New gadgets like the Poken issued by the social network Hyves [19] are supposed to replace the exchange of business cards since users only need to have their personal Poken device touch the one of their new encounters to exchange all data related to social networks (of course including Hyves but also Twitter, Facebook, Skype details, etc.). In our western society this seems just a fun way to exchange a multitude of data that users would like to exchange anyhow. In cultures like the business meeting ceremonies in Japan however, this simple touching of two small boxes could never be considered appropriate since you cannot show your social status information nor read the other's data during the hand-off of the information and consequently the next steps of greeting and taking initiatives in the meeting are not defined. A comparable analysis could be made of the use of mobile phones is public locations and public transport, and even during class. Apart from the actual users in this case the surrounding audience is stakeholder of the design and of the culture of use. Currently the loudness and sometimes rudeness of ringtones as well as the actual users' device-provoked loudness of voice as well as the misperception of the appropriateness of broadcasting the content of their conversations lead to a lot of negative experience by the involuntary audience.

The World Wide Web, the social networks, and the "social" gadgets and devices are being used by people that participate in many very different cultures. And these new tools themselves quickly lead to the change of existing cultures and even to the development of new cultures. Cultural values as well as the meaning and acceptance of symbols are criteria for acceptance and use and, by people's participation in worldwide use, will change. Consequently, designers

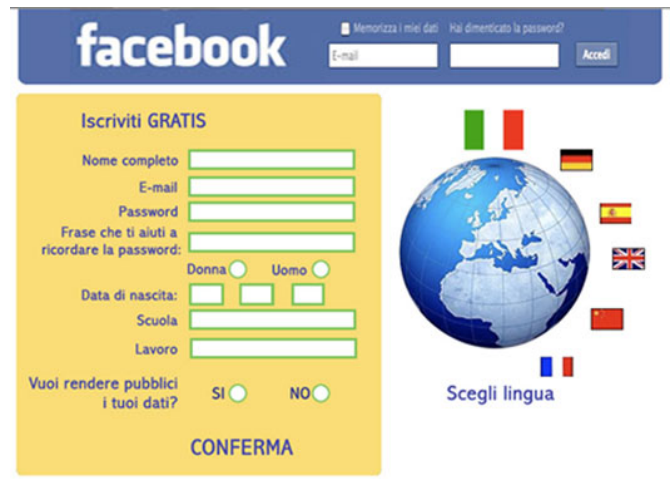

Fig. 1 Esthetic language choice

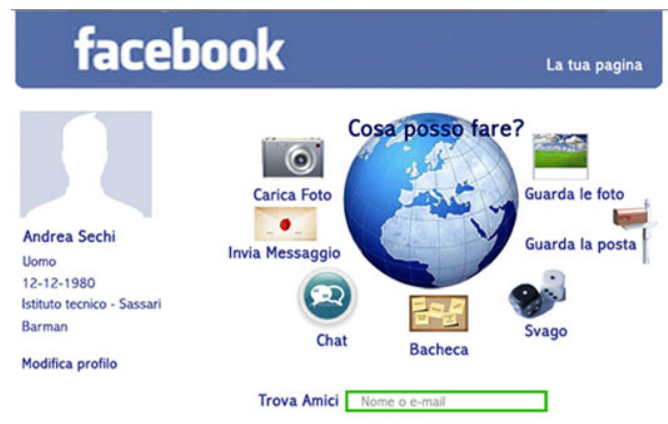

Fig. 2 Simplified dialogue 
need to be aware of the mutual effect of cultural values and network based communication. Based on the cultural values theory of Hofstede [15] new ways of analyzing these types of tools have been developed [17].

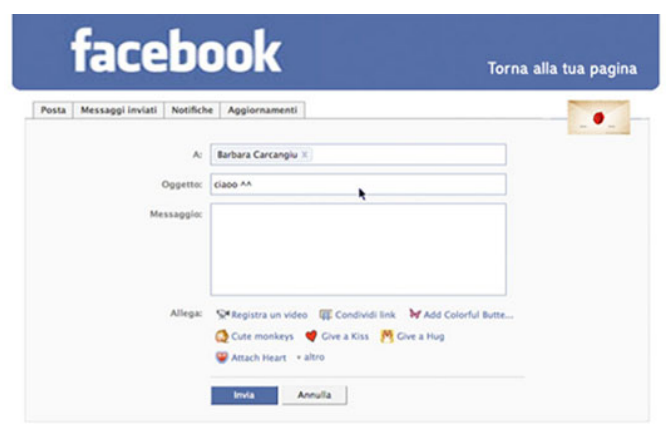

Fig. 3 Easy registration

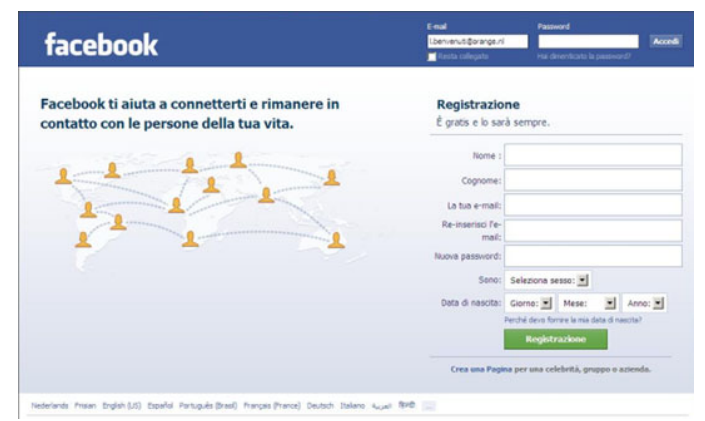

Fig. 4 Current Facebook

Fig. 5 (a)-(e) A struggle with colors and gender

\section{Observations on Teaching Design}

Teaching in different countries to students in different disciplines is both a challenge and an opportunity. Different situations result in different student cultures and teaching university cultures to start with. Student cohorts quickly lead to new "generations" where the use of last generation's "new" gadgets and tools is already dated. At the same time, being a stakeholder in a variety of cultures allows the teacher to provide references and links and to present students with examples of design challenges from different worlds. The current section will illustrate the current design struggles where cultural issues as well as the problems of intended and lived experience seem to stimulate the awareness of design students.

1. Facebook for a "new" culture

Students of the Faculty of Architecture, department of Design, at the University of Sassari, Italy, decided to redesign a social network tool. These students were certainly no experts in Software Engineering, but they could handle tools like Flash and drawing tools. In their local culture Facebook was in fact heavily used, but there were lots of complaints: the interface was confusing and requested sophisticated knowledge of the English language; for each user task many steps were needed, and there were frequent complaints about the need to remember passwords and email addresses. During teaching they were presented examples of Computer Science design students from other countries.

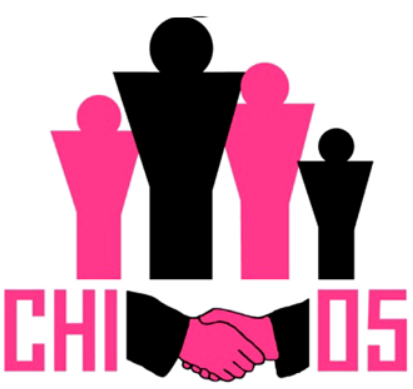

Community, Safety. Technology

(b)

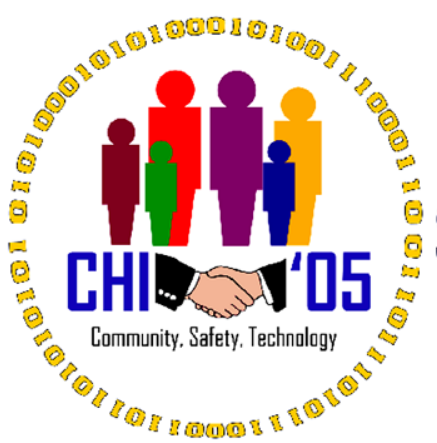

(d)

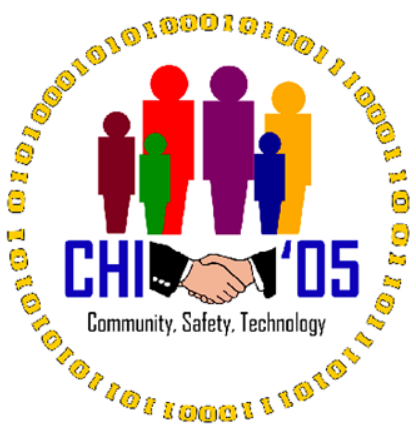

(e) 
The course strongly suggested them to be very analytic at the start as well as to be explicit about any design decision, an attitude that was relatively new to their type of curriculum. According to the design approach advocated by the teacher [22] they started with a task analysis where they discovered the goals of the original designer of Facebook changed from (according to the students) "contact for all students in the world" in 2004 to "network for everybody with a security age limit of 13 years" in 2007 . They found the goals of Facebook use in their culture to be mainly: meeting friends, business contacts, and advertising. Based on the identified problems and goals, they redesigned the tool.

Their design solution facilitated a novel feature to easy switch between multiple languages by choosing the appro-

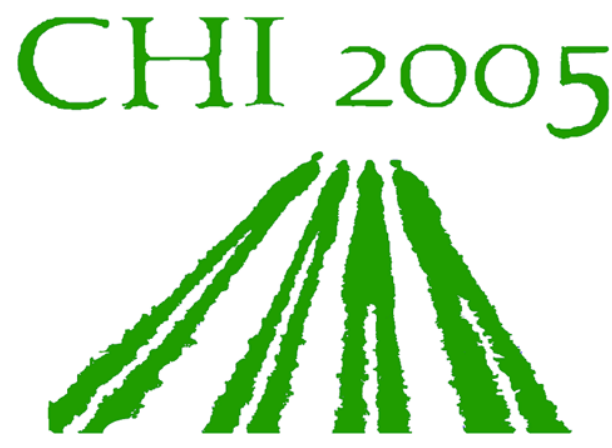

Fig. 6 Visuals for CHI 2005: meeting people priate icon (Fig. 1), cleared up the interface and redesigned the dialogue to need fewer steps than currently needed to move between functionalities like pictures, chat, mail, etc. (Fig. 2), and they simplified and supported registration (Fig. 3), compared to the current sign-up screen with language choice "hidden" at the bottom (Fig. 4). The students' final presentation showed awareness of cultural issues, as well as insight in the need for an analytical approach and for explicit decisions.

\section{Visual design in a Computer Science world}

Computer Science students at the Vrije Universiteit Amsterdam were challenged to develop the visual identity for CHI 2005, the annual international conference on humancomputer interaction sponsored by ACM SIGCHI. The conference committee for CHI 2005 was the client, an international group with a majority of North Americans, a distribution that is characteristic for the audience of the conference.

One of the student groups decided to take the international meeting of people as their visual theme, implemented as a group of people and a hand-shake. Figures 5a-e shows the development of their visuals as well as their struggle with colors and gender characteristics of the hands.

Obviously, none of the proposals was accepted in the culture of political correctness of the North Americans. Another student group developed a neutral way to represent people meeting, see Fig. 6 . This design could readily be accepted, and the (Computer Science) students subsequently

Fig. 7 Website for CHI 2005

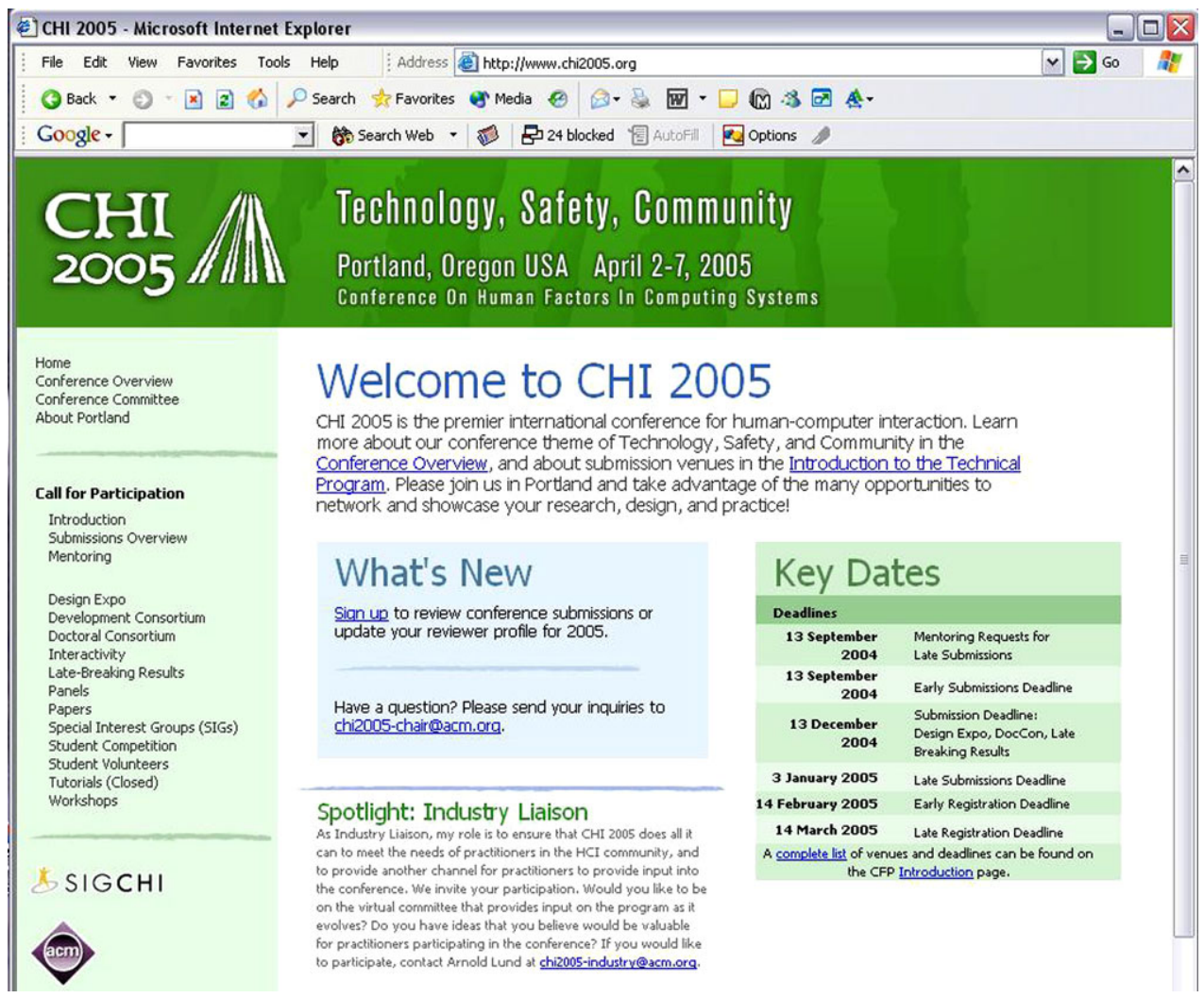


Fig. 8 Architecture of the entrance gate for CHI 2005

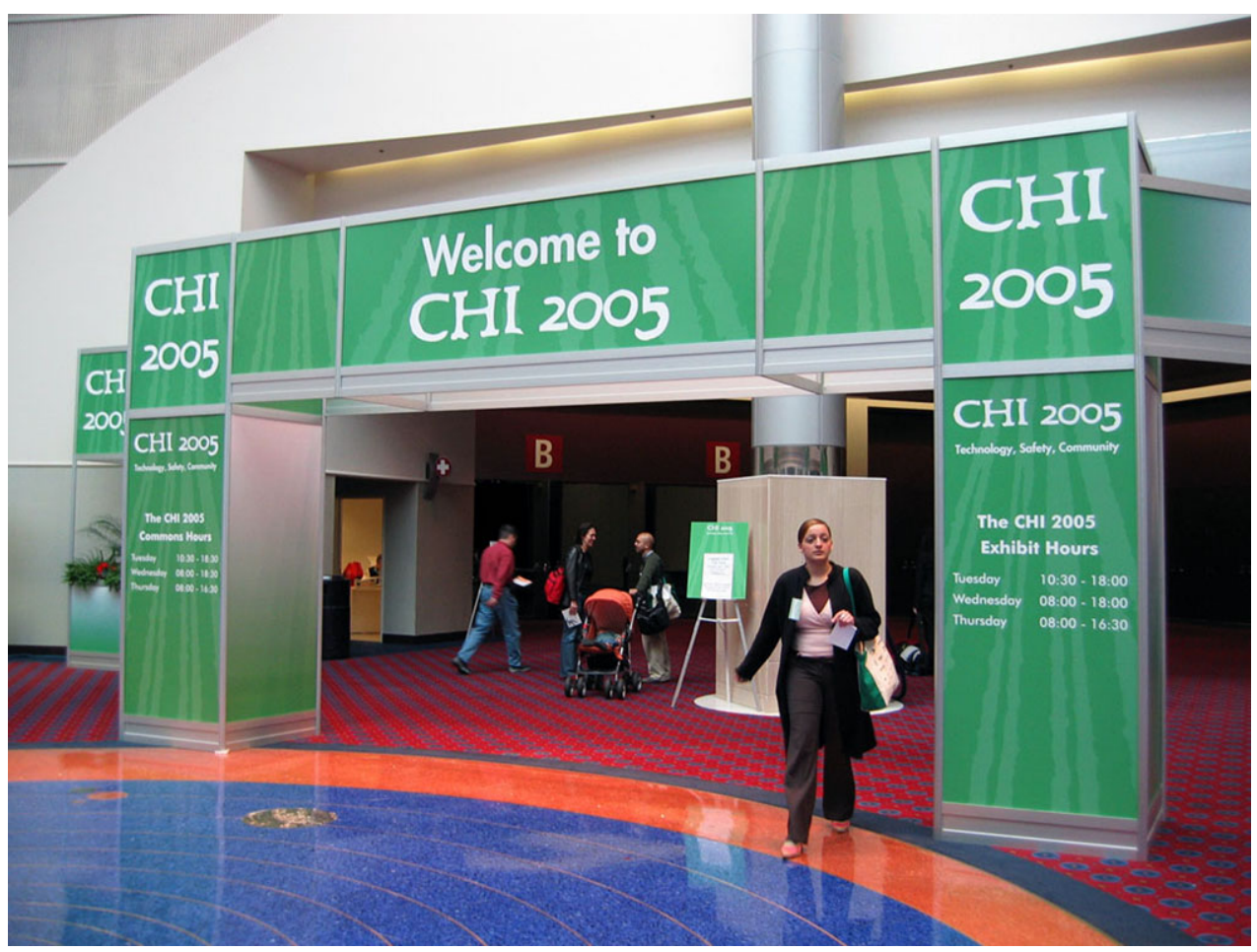

Fig. 9 Leaflet designed for IFIP TC13, applying a hyperlink metaphor

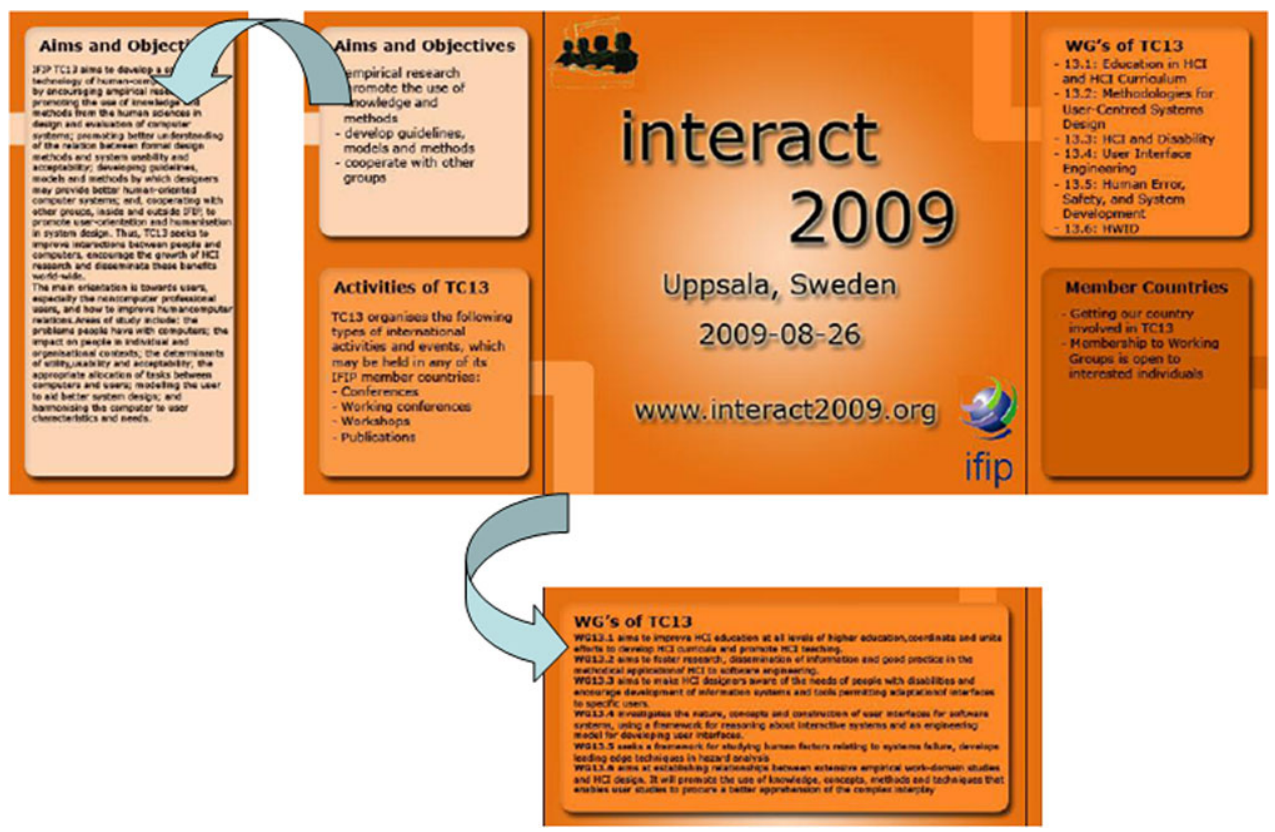

managed to develop not only the website visuals (Fig. 7) but many other representations that turned out to be applicable for print, for T-shirts, and even for the architecture of the entrance gate (Fig. 8).

\section{Paperwork inspired by hypertext}

The Dutch Open University delivers tuition to adult students that mostly have full time jobs and families. On average they can spend only 15 hours a week on their aca- demic study. As part of their Master program in Technical Computer Science some of these students take a course on Visual Design. In a recent course they were requested to design a website and related paper artifacts for IFIP's Technical Committee on Human-Computer Interaction, TC13. One of the designs shows how a typical computer science concept, hyperlinks, can be translated to paper.

Figure 9 represents a leaflet for TC13, where the front shows introductory entrances that lead both by a color code 
and by a colored pathway to the elaborated information at the backside. Obviously, the computer science students all agreed this was a nice and creative solution, however the client of design (the members of TC13) decided to choose another one that showed a much more traditional linear way of presenting the information. The computer science culture of the designers clearly did not match the client. A real test with the intended users of the leaflet (an international audience of professionals in computer science) could not be performed. We can only speculate how these would have experienced the rejected design.

\section{Conclusions}

Lessons from the history of human cultural developments can be applied to the design of computer supported artifacts and facilities. In this contribution we have shown how the focus of user centered design moved from only functionality through the addition of usability and experience to the inclusion of cultural awareness. Design as a profession continues to meet new challenges. Teaching design seems an ideal way to learn: through the diversity of students' cultures and through the continuous changes in technologysupported culture. However, attention to experience and culture does not allow designers to move away from a sound start in analysis, nor does it make explicit design decisions and design space analysis superfluous.

Open Access This article is distributed under the terms of the Creative Commons Attribution License which permits any use, distribution, and reproduction in any medium, provided the original author(s) and the source are credited.

\section{References}

1. Apple Special Event (2010) January 2010, retrieved March 14, 2010, from events.apple.com.edgesuite.net/1001q3f8hhr/event/ index.html

2. Beyer H, Holtzblatt K (1998) Contextual design: defining customer-centered systems. Morgan Kaufmann, San Francisco

3. Bradford W (2010) Molière died onstage in green. Retrieved March 14, 2010, from plays.about.com/od/ experiencesandanecdotes/a/moliereDeath.htm

4. Churchill E (2005) Privacy settings of a million Flickr users. Presentation cited by Michael Arrington on Oct 29, 2008, retrieved March 14, 2010, from techcrunch.com/2008/10/29/user-privacyconcerns-by-geography-a-flickr-study

5. Council Directive 90/270/EEC (1990) European agency for safety and health at work

6. Dialogue principles ISO 9241-10 (1996) Ergonomic requirements for office work with visual display terminals (VDTs) Part 10. International Organization for Standardization (ISO) Geneva, Switzerland
7. Dror IE, Harnad S (eds) (2008) Cognition distributed: how cognitive technology extends our minds. Benjamins, Amsterdam

8. Dunbar RIM (1993) Coevolution of neocortical size, group size and language in humans. Behav Brain Sci 16(4):681-735

9. Dzida W (1989) The development of ergonomic standards. ACM SIGCHI Bull 20(3):35-42

10. Eason K (2009) In memoriam: professor Brian Shackel, 19272007. Interact Comput 21(5-6):375-376

11. Freedberg D, Gallese V (2007) Motion, emotion and empathy in esthetic experience. Trends Cogn Sci 11(5):197-203

12. General Motors (1936) Frigidaire advertisement. The Palm Beach Post, Mar 8, 1936 West Palm Beach, FL

13. Gulli A (2009) Distribution of Facebook users. Antonio Gulli's coding playground, November 25, 2009, retrieved March 14, 2010, from codingplayground.blogspot.com/2009/11/distributionof-facebook-users-300m.html

14. Henninger S, Haynes K, Reith KM (1995) A framework for developing experience-based usability guidelines. In: Proceedings of the symposium on designing interactive systems, Ann Arbor, MI, August, 1995, pp 43-53

15. Hofstede G, Hofstede GJ, Minkov M (2010) Cultures and organizations: software of the mind. McGraw-Hill, New York. Revised and expanded 3rd edn.

16. Hutchins E (1995) Cognition in the wild. MIT Press, Cambridge

17. Marcus A, Gould EW (2000) Cultural dimensions and global Web user-interface design. Interactions 7(4):32-46

18. Owen J (2009) Bone flute is oldest instrument, study says. National Geographic News, June 24, 2009

19. Poken (2010) retrieved March 14, 2010, from www.poken.com/ web/guest

20. UMBC Global Distribution of Twitter Users (2007) UMBC eBiquity Research Group, University of Maryland, Baltimore, retrieved March 14, 2010, from ebiquity.umbc.edu/blogger/2007/04/ 15/global-distribution-of-twitter-users

21. van Beek W (2009) Online suicide ook painless? Retrieved March 14, 2010, from www.dutchcowboys.n1/web2dot0/18615

22. van der Veer GC, van Welie M (2003) Designing for users and tasks from concepts to handles. In: Diaper D, Stanton N (eds) The handbook of task analysis for human-computer interaction. Lawrence Erlbaum, Mahwah, pp 155-173

23. Vyas D, van der Veer GC (2006) Experience as meaning: some underlying concepts and implications for design. In: Proceedings of 13th European conference on cognitive ergonomics (ECCE'06). ACM, New York, pp 81-91

24. Wells R (2007) Superstitious survival-Avoiding bad luck in Italy. The Florentine issue 56/2007/May 17, 2007

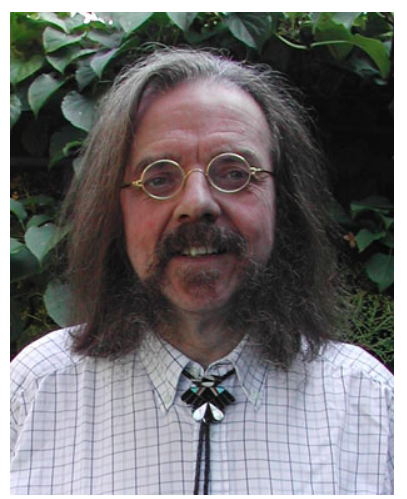

Gerrit C. van der Veer is Emeritus Professor of Multimedia and Culture at Vrije Universiteit Amsterdam and currently Professor of Human-Computer Interaction at the Open University Netherlands and Thesis supervisor of the Department Human-Media Interaction at the University Twente (the Netherlands). Gerrit is President of the European Association of Cognitive Ergonomics (EACE), Honorary Member of Chi Nederland and President of ACM SIGCHI 